\title{
Stereospermum suaveolens (Roxb.) DC. Shows Potential in vivo and in vitro Bioactivities
}

\author{
Md. Moniruzzaman', Md. Ruhul Kuddus², Mohammad Rashedul Haque ${ }^{2}$, \\ A. M. Sarwaruddin Chowdhury ${ }^{1}$ and Mohammad A. Rashid ${ }^{2}$ \\ ${ }^{1}$ Department of Applied Chemistry and Chemical Engineering, Faculty of Engineering and Technology \\ University of Dhaka, Dhaka-1000, Bangladesh \\ ${ }^{2}$ Department of Pharmaceutical Chemistry, Faculty of Pharmacy, University of Dhaka \\ Dhaka-1000, Bangladesh
}

(Received: October 1, 2018; Accepted: December 3, 2018; Published (web): December 10, 2018)

\begin{abstract}
The methanol extract of Stereospermum suaveolens (Roxb.) DC was investigated for antidiabetic, antidiarrheal and analgesic activities in Swiss Albino mice. Antidiabetic activity was evaluated by oral glucose tolerance test where the crude extract of S. suaveolens $(400 \mathrm{mg} / \mathrm{kg}$ b.w.) exhibited $56.10 \%$ reduction of blood glucose level as compared to $58.53 \%$ by standard glibenclamide $(0.1 \mathrm{mg} / \mathrm{kg}$ b.w.). In the castor oil-induced diarrhea in mice, the plant extract, at the dose of $400 \mathrm{mg} / \mathrm{kg}$ b.w. demonstrated $42.11 \%$ reduction of diarrheal feces, while the standard loperamide revealed $57.89 \%$ reduction of diarrheal feces. The analgesic activity of $S$. suaveolens was assessed by both radiant heat tail-flick and acetic acid-induced writhing test. The methanolic extract and different Kupchan fractions of S. suaveolens were also subjected to screening for total phenolic content, DPPH free radical scavenging assay, membrane stabilizing, thrombolytic and antimicrobial activities. In the DPPH assay, the aqueous soluble fraction of methanolic extract revealed highest antioxidant properties with $\mathrm{IC}_{50}$ value of $18.99 \mu \mathrm{g} / \mathrm{ml}$. The membrane stabilizing activity was assessed by hypotonic solution- and heat-induced methods and was compared with standard acetyl salicylic acid. In hypotonic solution-induced haemolysis, the hexane and carbon tetrachloride soluble fraction inhibited $54.42 \%$ and $52.67 \%$ haemolysis of RBCs, respectively. On the other hand, in heat-induced haemolysis, the chloroform soluble fraction inhibited the haemolysis of RBC by $57.10 \%$ as compared to $72.09 \%$ produced by acetyl salicylic acid. In antimicrobial assay by disc diffusion method, only the hexane and carbon tetrachloride soluble fractions demonstrated moderate antimicrobial activity (zone of inhibition $=7.0-15.0 \mathrm{~mm}$ ) against the test organisms.
\end{abstract}

Key words: Stereospermum suaveolens, antidiabetic, anti-diarrheal, analgesic, antioxidant, membrane stabilizing, thrombolytic, antimicrobial.

\section{INTRODUCTION}

Since ancient civilization, herbs and plants products have been used for treatment of wide range of diseases. Especially, people living in rural areashave been using indigenous plants as medicines. Therefore, the World Health Organization (WHO) is now actively encouraging the use of herbal medicines, which they have been traditionally used for centuries. ${ }^{1,2}$

Correspondence to: Mohammad A. Rashid Tel.: +88-02-9661900-73, Extn.8137; Fax: +88-02-9667222 E-mail: r.pchem@yahoo.com

Dhaka Univ. J. Pharm. Sci. 17(2): 257-263, 2018 (December) DOI: http://dx.doi.org/10.3329/dujps.v17i2.39184
Stereospermum suaveolens (Roxb.) DC. (Bengali name: parul, atkopali; Family: Bignoniaceae) is a medicinal plant that isnative to Bangladesh, India and Myanmar. In Bangladesh, it is found in forests of Chittagong, Chittagong Hill Tracts, and the northern districts. ${ }^{3} \quad$ The plant has been studied pharmacologically for its anti-inflammatory, anticancer, hepatoprotective, antihyperglycemic and antioxidant activities. ${ }^{4}$ Traditionally, roots and bark of this plant are used for many diseases like asthma, inflammations, pain, blood disorders, fevers, liver disorders etc. ${ }^{5}$ Decoction of roots is used in puerperal fevers. Flowers with honey are used to stop cough. ${ }^{6}$ 
Phytoconstituents such as 6-O-glucosyls-cutellarein ${ }^{7}$, dinatin, dinatin-7-glucuroniside ${ }^{8}$, dinatin 7glucuronide $^{7}$, quinones, stereochenols $\mathrm{A}$ and $\mathrm{B}$, naphthoquinones, sterekunthal $\mathrm{B}$,sterequinone $\mathrm{C}^{9}$ and stereolen $\sin ^{10}$ have previously been reported from the leaves of this plant.

As part of our continuing studies on medicinal plants of Bangladesh ${ }^{11,12}$, we evaluated the biological activities of methanol extract of $S$. suaveolens in order to find out the rationale for its folk uses and we, herein, report the results of our preliminary investigation.

\section{MATERIALS AND METHODS}

Plant material. Both leaf and stem bark of $S$. suaveolens were collected from Baldha Garden, Wari, Dhaka, Bangladesh, in October, 2015 and identified in Bangladesh National Herbarium, Mirpur, Dhaka where a voucher specimen has been deposited (Accession No. DACB-43522).

The plant samples were air dried and ground to a coarse powder using a grinding machine at the laboratory of Dept. of Applied Chemistry and Chemical Engineering, University of Dhaka. The powdered materials (350 gm) of both leaf and stem bark of $S$. suaveolens were mixed, then macerated in 2.5 liter of methanol for 15 days and finally, filtered through Whatman filter paper number 1 . The filtrate was concentrated using rotary evaporator at $40^{\circ} \mathrm{C}$ under reduced pressure. About $5 \mathrm{~g}$ of the concentrated extract was subjected to solvent-solvent partitioning following the modified Kupchan method $^{13}$ to yield hexane, carbon tetrachloride, chloroform and aqueous soluble fractions. Then the crude extract and its Kupchan fractions were studied separately for the evaluation of biological activities.

Drugs and reagent. Methanol, acetic acid, Tween 80, glibenclamide, (Square Pharmaceuticals Ltd.), loperamide (Square Pharmaceuticals Ltd.), normal saline (Opsonin Pharmaceuticals Ltd.), morphine (Gonoshasthaya Pharmaceuticals Ltd.), diclofenac-Na (Essential Drugs Company Ltd.), and castor oil were collected from local market. All other chemicals and solvents were of analytical grade.
Experimental animal. Swiss Albino mice (28$30 \mathrm{gm}$ ) of either sex aged 4-5 weeks were collected from the Animal Resources Branch of the International centre for Diarrheal Diseases and Research, Bangladesh (icddr,b). They were housed in standard polypropylene cages and kept at room temperature $\left(24 \pm 2^{\circ} \mathrm{C}\right)$ and relative humidity (60$70 \%$ ) in a 12 hour light-dark cycle and are fed with icddr,b formulated diet and water ad libitum.

Anti-diabetic activity. Anti-diabetic activity of the crude methanolic extract of $S$. suaveolens was determined in glucose-induced diabetic mice. ${ }^{13}$ Experimental animals were divided into four groups consisting of four mice each. Before administration of drug, the blood glucose levels of mice of all groups were determined and the average value was found as $5.50 \mathrm{mmol} / \mathrm{l}$. The positive control group received glibenclamide ( $3 \mathrm{mg} / \mathrm{kg}$, orally) while the test groups received the methanol extract of $S$. suaveolens orally at the dose of 200- and 400- $\mathrm{mg} / \mathrm{kg}$ b.w. After $30 \mathrm{~min}$, all mice were fed with $1.0 \mathrm{ml}$ of $10 \%$ glucose solution in water. Then, the glucose level of each mouse was recorded at 30, 90 and 150 min with a simple glucometer using strips technique. In this experiment, the responses of the extract and glibenclamide treated groups were compared with the animals in the control group.

Anti-diarrheal activity. Anti-diarrheal activity of the crude methanol extract of $S$. suaveolens was determined following the published method $^{14}$ with slight modification. Sixteen Swiss Albino mice were divided into four groups consisting of four mice in each group. The negative control group received vehicle ( $1 \%$ Tween- 80 in water) at $10 \mathrm{ml} / \mathrm{kg}$ b.w. orally, while the positive control group received loperamide $(50 \mathrm{mg} / \mathrm{kg}$ b.w.) orally. The test group received the methanolic extract of $S$. suaveolens at 200- and $400-\mathrm{mg} / \mathrm{kg}$ b.w. orally. After 30 minutes interval to ensure proper absorption of the administered substance, $1.0 \mathrm{ml}$ of castor oil was fed to each mouse to induce diarrhea. Each animal was placed in an individual case, the floor of which was lined with blotting paper. Each of the mice was observed for four hours to record the number of stool 
giving instances. The average of total number of stool given by the test group, and the control group was compared and the percent inhibition of defecation in mice was calculated by using the following equation $\%$ inhibition $=\left(\mathrm{M}_{\mathrm{C}}-\mathrm{M}_{\mathrm{T}}\right) / \mathrm{M}_{\mathrm{C}} \times 100$;

Where, $\mathrm{M}_{\mathrm{C}}=$ Mean defecation of control and $\mathrm{M}_{\mathrm{T}}=$ mean defecation of test sample.

Central analgesic activity. The central analgesic activity of methanolic crude extract of $S$. suaveolens was determined by radiant heat tail flick method. ${ }^{15}$ Test animals were divided into four groups having four mice in each group. In this experiment, the test groups received the methanolic extract of $S$. suaveolens (200- and 400-mg/kg b.w. orally), while the positive and negative control mice were treated with morphine $(4 \mathrm{mg} / \mathrm{kg}$ b.w.) subcutaneously and normal saline, respectively. Thirty minutes after administration, the tail of each mouse was kept immersed in hot water at $54^{\circ} \mathrm{C}$. The time required to withdraw the tail (tail flick) was recorded. The tail flicking time was measured by stopwatch. Then the percent (\%) time of elongation due to the effect of various fraction and standard were calculated using the following formula:

$\%$ elongation of reaction time $=$ (Average reaction time of the test group - Average reaction time of control group)/ Average reaction time of control group.

Peripheral analgesic activity. The peripheral analgesic activity of $S$. suaveolens extract was determined by acetic acid-induced writhing inhibition as described by Koster and Turner. ${ }^{16}$ Experimental mice were divided into four groups with four mice in each group. Here, the test groups received the plant extract at 200- and $400-\mathrm{mg} / \mathrm{kg}$ b.w., while the positive and negative control mice were treated with diclofenac-Na (50 mg/kg b.w.) and normal saline, respectively. The percent (\%) inhibition of writhing in comparison to control group was taken as an index of analgesia and was calculated using the following formula:

$$
\% \text { of inhibition }=\left(\mathrm{W}_{\mathrm{C}^{-}}-\mathrm{W}_{\mathrm{T}}\right) \times 100 / \mathrm{W}_{\mathrm{C}}
$$

Where, $\mathrm{W}_{\mathrm{C}}$ is the average number of writhing reflex in the control group and $\mathrm{W}_{\mathrm{T}}$ is the average number of writhing reflex in the test group.

Total phenoliccontent analysis. The crude methanolic extract of $S$. suaveolens and its organic partitionates were subjected to assay for total phenolic compounds involving Folin-Ciocalteu reagent as an oxidizing agent and gallic acid as standard.$^{17}$ Exactly $2.5 \mathrm{ml}$ of Folin-Ciocalteu reagent and $2.0 \mathrm{ml}$ of sodium carbonate $(7.5 \% \mathrm{w} / \mathrm{v})$ solution were added to extract solution $(2 \mathrm{mg} / \mathrm{ml})$ in water. After 20 minutes of incubation at room temperature, the absorbance was measured at $760 \mathrm{~nm}$ using a UVvisible spectrophotometer. The total phenolics was quantified by calibration curve obtained by measuring the absorbance values of known concentration of gallic acid $(0-100 \mu \mathrm{g} / \mathrm{ml})$ and were expressed as mg of GAE (gallic acid equivalent)/gm of the dried extract.

Free radical scavenging activity. The free radical scavenging activity (antioxidant capacity) of the crude methanolic extract of $S$. suaveolens and its Kupchan partitionates on the stable radical 1,1diphenyl-2-picrylhydrazyl (DPPH) was estimated by the method established by Brand-Williams et al. ${ }^{18}$

Test for thrombolytic activity. The thrombolytic activity of the crude methanolic extract of $S$. suaveolens and its Kupchan partitionates was evaluated following the method developed by Prasad et al. ${ }^{19}$ using streptokinase as standard.

Test for membrane stabilizing activity. The membrane stabilizing activity of the crude methanolic extract of $S$. suaveolens and its Kupchan partitionates was assessed following the method of hypotonic-and heat-induced erythrocyte hemolysis designed by Shinde et al. ${ }^{20}$ using acetyl salicyclic acid as standard.

Test for antimicrobial activity. The preliminary antimicrobial activity of the crude methanolic extract of $S$. suaveolens and partitionates were assessed by the disc diffusion method ${ }^{21}$ using standard ciprofloxacin $(30 \mu \mathrm{g})$ and fluconazole $(30 \mu \mathrm{g})$ as reference standards. 


\section{RESULTS AND DISCUSSION}

In the anti-diabetic assay, after 30 minutes of administration the methanolic crude extract of $S$. suaveolens at $200-$ and $400-\mathrm{mg} / \mathrm{kg}$ b.w. reduced blood glucose level by $37.58 \%$ and $56.10 \%$, respectively as compared to $58.53 \%$ reduced by standard glibenclamide ( $0.1 \mathrm{mg} / \mathrm{kg}$ b.w.) (Table 1$)$.
In the castor oil-induced diarrhea, the crude methanol extract of $S$. suaveolens produced marked anti-diarrheal effect in the mice, as shown in table 2. Here, the plant extract at the dose of 200- and 400$\mathrm{mg} / \mathrm{kg} \mathrm{b}$.w. demonstrated reduction of diarrheal feces by $21.05 \%$ and $42.11 \%$, respectively when compared with loperamide which reduced the same by $57.89 \%$. In evaluation of anti-diarrheal activity, the crude extract showed statistically significant activity.

Table 1. Anti-diabetic activity of methanol extract of S. suaveolens.

\begin{tabular}{|c|c|c|c|c|c|c|}
\hline \multirow{3}{*}{ Test groups } & \multicolumn{4}{|c|}{ Average blood glucose level (mmol/l) } & \multirow{2}{*}{\multicolumn{2}{|c|}{$\%$ Inhibition }} \\
\hline & \multirow[b]{2}{*}{ Before treatment } & \multicolumn{3}{|c|}{ After treatment } & & \\
\hline & & $30 \mathrm{~min}$ & $90 \mathrm{~min}$ & 150min & $60 \mathrm{~min}$ & $120 \mathrm{~min}$ \\
\hline Control & $5.33 \pm 0.60$ & $23.17 \pm 1.51$ & $18.97 \pm 1.37$ & $16.23 \pm 1.05$ & - & - \\
\hline $\begin{array}{l}\text { Glibenclamide } \\
\text { (0.1 mg/kg b.w.) }\end{array}$ & $5.73 \pm 1.05$ & $24.13 \pm 0.86$ & $9.4 \pm 0.26$ & $6.73 \pm 0.70$ & 51.45 & 58.53 \\
\hline $\begin{array}{c}\text { MESS } \\
\text { (200 mg/kg b.w.) }\end{array}$ & $5.50 \pm 0.33$ & $26.97 \pm 0.75$ & $14.53 \pm 1.42$ & $10.13 \pm 0.27$ & 23.40 & 37.58 \\
\hline $\begin{array}{c}\text { MESS } \\
\text { (400 mg/kg b.w.) }\end{array}$ & $5.77 \pm 0.19$ & $25.23 \pm 0.46$ & $10.73 \pm 0.56$ & $7.13 \pm 0.60$ & 43.44 & 56.10 \\
\hline
\end{tabular}

Values are expressed as mean \pm SEM $(n=4) . p<0.05$ significant when compared to negative control, MESS $=$ Methanolic extract of $S$. suaveolens

Table 2. Anti-diarrheal activity of methanol extract of $S$. suaveolens.

\begin{tabular}{lcc}
\hline Test groups & $\begin{array}{c}\text { No. of diarrheal feces } \\
\text { Mean } \pm \text { SEM }\end{array}$ & $\begin{array}{c}\text { \%Reduction of } \\
\text { diarrheal feces }\end{array}$ \\
\hline Control & $6.33 \pm 1.41$ & - \\
Loperamide (50 mg/kg b.w.) & $2.67 \pm 0.33$ & 57.89 \\
MESS (200 mg/kg b.w.) & $5.0 \pm 1.53$ & 21.05 \\
MESS (400 mg/kg b.w.) & $3.67 \pm 1.20$ & 42.11 \\
\hline
\end{tabular}

Values are expressed as mean \pm SEM $(n=4)$.

The central analgesic effect of methanol extract of S.suaveolens is presented in table 3. In this test, the extract effectively elongated the reaction time. The percent (\%) elongation time was recorded at 30, 60 and 90 min after administration of drug samples in the experimental mice. About $30 \mathrm{~min}$ after administration, the methanolic crude extract, at the doses of 200- and 400-mg/kg b.w. revealed elongation of reaction time by $69.23 \%$ and $132.30 \%$, respectively while the standard morphine $(4 \mathrm{mg} / \mathrm{kg}$ b.w.) showed $200.09 \%$ of elongation. After $60 \mathrm{~min}$, the tested extract exhibited highest elongation as $185.59 \%$ and $259.21 \%$, respectively compared to $313.32 \%$ by morphine. The central analgesic property was found to increase till $60 \mathrm{~min}$ and then decreased with time.

In peripheral analgesic activity study, the crude extract significantly decreased the number of acetic acid-induced abdominal writhings in mice (Table 4). Statistical evaluation of the data confirmed promising analgesic activity of $S$. suaveolens. Here, the plant extract at $200-$ and $400-\mathrm{mg} / \mathrm{kg}$ b.w. showed $31.82 \%$ 
and $48.48 \%$ inhibition of writhing, respectively as compared to $65.15 \%$ inhibition produced by the standard diclofenac-Na. Both in the acetic acidinduced writhing and tail flick method, the crude methanolic extract showed significant analgesic activity. As the extract appeared to be active in both animal models of nociception, it may possess peripherally and centrally acting compounds for its antinociceptive action.

Table 3. Central analgesic activity of methanol extract of S. suaveolens.

\begin{tabular}{|c|c|c|c|c|c|c|c|c|}
\hline \multirow{2}{*}{ Test groups } & \multicolumn{4}{|c|}{ Mean of tail immersion \pm SEM } & \multicolumn{4}{|c|}{$\%$ Elongation } \\
\hline & $0 \mathrm{~min}$ & $30 \mathrm{~min}$ & $60 \mathrm{~min}$ & $90 \mathrm{~min}$ & $0 \mathrm{~min}$ & $30 \mathrm{~min}$ & $60 \mathrm{~min}$ & $90 \mathrm{~min}$ \\
\hline Control & $1.76 \pm 0.03$ & $1.80 \pm 0.03$ & $1.99 \pm 0.05$ & $1.96 \pm 0.05$ & - & - & - & - \\
\hline $\begin{array}{l}\text { Morphine } \\
\text { (4 mg/kg b.w.) }\end{array}$ & $1.76 \pm 0.04$ & $5.40 \pm 0.14$ & $8.23 \pm 0.16$ & $7.29 \pm 0.90$ & -0.05 & 200.09 & 313.32 & 272.50 \\
\hline $\begin{array}{l}\text { MESS } \\
(200 \mathrm{mg} / \mathrm{kg} \text { b.w.) }\end{array}$ & $1.75 \pm 0.09$ & $3.04 \pm 0.25$ & $5.68 \pm 0.30$ & $4.88 \pm 0.35$ & -0.13 & 69.23 & 185.59 & 149.04 \\
\hline $\begin{array}{l}\text { MESS } \\
(400 \mathrm{mg} / \mathrm{kg} \text { b.w.) }\end{array}$ & $1.75 \pm 0.10$ & $4.18 \pm 0.26$ & $7.15 \pm 0.19$ & $6.35 \pm 0.50$ & -0.57 & 132.30 & 259.21 & 224.18 \\
\hline
\end{tabular}

Values are expressed as mean $\pm \operatorname{SEM}(n=4)$.

Table 4. Peripheral analgesic activity of methanol extract of $S$. suaveolens.

\begin{tabular}{|c|c|c|c|c|c|c|c|}
\hline \multirow{2}{*}{ Test groups } & \multicolumn{4}{|c|}{ Writhing count } & \multirow{2}{*}{$\begin{array}{l}\text { No. of writhing } \\
\text { Mean } \pm \text { S EM }\end{array}$} & \multirow{2}{*}{$\%$ Writhing } & \multirow{2}{*}{$\begin{array}{l}\text { \% Inhibition } \\
\text { of writhing. }\end{array}$} \\
\hline & M1 & M2 & M3 & M4 & & & \\
\hline Control & 18 & 15 & 17 & 16 & $16.50 \pm 0.76$ & 100 & - \\
\hline Diclofenac-Na 50 mg/kg b.w. & 7 & 5 & 5 & 6 & $5.75 \pm 0.58$ & 34.85 & 65.15 \\
\hline MESS 200 mg/kg b.w. & 13 & 12 & 9 & 11 & $11.25 \pm 1.04$ & 68.18 & 31.82 \\
\hline MESS 200 mg/kg b.w. & 8 & 7 & 9 & 8 & $8.0 \pm 0.50$ & 51.52 & 48.48 \\
\hline
\end{tabular}

Values are expressed as mean $\pm \operatorname{SEM}(n=4)$.

The total phenolic contents varied for the crude extract and its partitionates of $S$. suaveolens ranging from $2.13 \mathrm{mg}$ to $9.7 \mathrm{mg}$ of GAE/gm of dried extract (Table 5). The highest total phenolic was found in AQSF (9.7 mg of GAE/gm of dried extract) and the lowest in HSF (2.13 mg of GAE/gm of dried extract).

In the screening for antioxidant activity, the aqueous soluble fraction showed the highest activity with $\mathrm{IC}_{50}$ value of $18.99 \mu \mathrm{g} / \mathrm{ml}$ (Table 5). At the same time, the crude methanolic extract and its chloroform soluble fraction also exhibited significant antioxidant activity with $\mathrm{IC}_{50}$ value of 45.6 and $46.7 \mu \mathrm{g} / \mathrm{ml}$, respectively. These results denote the presence of antioxidant principles in the extractives.
In order to identify the drugs with the ability to promote lysis of blood clot from natural sources, the extractives of $S$. suaveolens were assessed for thrombolytic activity. Addition of $100 \mu \mathrm{l}$ streptokinase (SK), a positive control (30,000 I.U.) to the clots of human blood and subsequent incubation for 90 minutes at $37^{\circ} \mathrm{C}$, showed $64.2 \%$ lysis of clot. On the other hand, distilled water (negative control) showed negligible lysis of clot $(3.62 \%)$. The mean difference in percentage of clot lysis between positive and negative control was found to be statistically significant. In this study, all the samples showed mild to moderate activity where the aqueous soluble fractions exhibited $34.7 \%$ clot lysis (Table 5). 
The extractives of S. suaveolens (conc. 2.0 $\mathrm{mg} / \mathrm{ml}$ ) significantly protected the lysis of mice erythrocyte membrane induced by hypotonic solution and heat. The results were compared with standard acetyl salicylic acid $(0.10 \mathrm{mg} / \mathrm{ml})$ (Table 5). In hypotonic solution-induced haemolysis, the hexane

Table 5. Total phenolic content, free radical scavenging activity, thrombolytic activity and membrane stabilizing activity of different extracts of $S$. suaveolens.

\begin{tabular}{cccccc}
\hline \multirow{2}{*}{ Sample } & $\begin{array}{c}\text { mg of GAE/gm } \\
\text { extractive }\end{array}$ & $\mathrm{IC}_{50}(\mu \mathrm{g} / \mathrm{ml})$ & \% Clot lysis & $\begin{array}{c}\text { Hypotonic solution- } \\
\text { induced }\end{array}$ & Heat-induced \\
\hline MESS & $3.98 \pm 0.38$ & $45.6 \pm 2.4$ & $14.94 \pm 0.94$ & $33.05 \pm 3.46$ & $35.47 \pm 1.45$ \\
HSF & $2.13 \pm 0.12$ & $90.78 \pm 2.2$ & $23.06 \pm 0.36$ & $54.42 \pm 0.12$ & $55.33 \pm 4.84$ \\
CTSF & $3.43 \pm 0.30$ & $53.17 \pm 3.3$ & $26.03 \pm 1.24$ & $52.67 \pm 1.17$ & $40.05 \pm 8.26$ \\
CSF & $4.66 \pm 0.07$ & $46.70 \pm 1.95$ & $9.43 \pm 0.99$ & $42.33 \pm 6.30$ & $57.10 \pm 5.73$ \\
AQSF & $9.70 \pm 0.19$ & $18.99 \pm 0.88$ & $34.70 \pm 1.77$ & $22.90 \pm 6.71$ & $33.99 \pm 5.05$ \\
BHT & -- & $17.77 \pm 1.83$ & -- & -- & -- \\
AA & -- & $2.80 \pm 0.74$ & -- & -- & -- \\
SK & -- & -- & $64.23 \pm 0.17$ & -- & $72.09 \pm 3.18$ \\
ASA & -- & -- & -- & $74.64 \pm 2.44$ & \\
\hline
\end{tabular}

Values are expressed as mean \pm SEM $(n=3) . H S F=$ Hexane soluble fraction, $\mathrm{CTSF}=$ Carbon tetrachloride soluble fraction, $\mathrm{CSF}=$ Chloroform soluble fraction, $\mathrm{AQSF}=$ Aqueous soluble fraction of methanolic extract of $S$. suaveolens, BHT = Butylated hydroxyl toluene, $\mathrm{AA}=$ Ascorbic acid, SK = Streptokinase, $\mathrm{ASA}=$ Acetyl salicylic acid.

Table 6. Antimicrobial activity of different extracts of S. suaveolens.

\begin{tabular}{|c|c|c|c|}
\hline \multirow[b]{2}{*}{ Microorganisms } & \multicolumn{3}{|c|}{ Diameter of zone of inhibition (mm) } \\
\hline & $\begin{array}{c}\mathrm{HSF} \\
(500 \mu \mathrm{g} / \mathrm{disc})\end{array}$ & $\begin{array}{c}\text { CTSF } \\
(500 \mu \mathrm{g} / \mathrm{disc}) \\
\end{array}$ & $\begin{array}{c}\text { Ciprofloxacin } \\
(30 \mu \mathrm{g} / \mathrm{disc})\end{array}$ \\
\hline \multicolumn{4}{|l|}{ Gram positive bacteria } \\
\hline Bacillus cereus & 13 & 12 & 39 \\
\hline B. megaterium & 12 & 15 & 42 \\
\hline B. subtilis & 10 & 9 & 45 \\
\hline Sarcina lutea & 9 & 10 & 45 \\
\hline Staphylococcus aureus & - & 9 & 42 \\
\hline \multicolumn{4}{|l|}{ Gram negative bacteria } \\
\hline Escherichia coli & 8 & 10 & 43 \\
\hline Pseudomonas aeruginosa & 8 & 10 & 44 \\
\hline Salmonella Paratyphi & 8 & 13 & 40 \\
\hline S. Typhi & 10 & 8 & 41 \\
\hline Shigella dysenteriae & 10 & 11 & 42 \\
\hline Sh. boydii & 9 & - & 42 \\
\hline Vibrio mimicus & 8 & 8 & 40 \\
\hline V. parahemolyticus & - & 10 & 43 \\
\hline Fungi & \multicolumn{2}{|c|}{ Fluconazole $(30 \mu \mathrm{g} /$ disc $)$} & \\
\hline Aspergillus niger & 10 & 8 & 40 \\
\hline Candida albicans & 9 & 12 & 41 \\
\hline Sacharomyces cerevisiae & 8 & - & 38 \\
\hline
\end{tabular}

and carbon tetrachloride soluble fractions inhibited haemolysis of RBC by 54.42 and $52.67 \%$, respectively as compared to $74.64 \%$ produced by acetyl salicylic acid. The chloroform soluble fraction of methanolic crude extract also revealed significant inhibition of haemolysis of RBCs. On the other hand, in heat-induced haemolysis, both chloroform and hexane soluble fractions inhibited $57.10 \%$ and $55.33 \%$ haemolysis of $\mathrm{RBC}$, respectively as compared to $72.09 \%$ produced by acetyl salicylic acid. 
During screening for antimicrobial activity, only hexane (HSF) and carbon tetrachloride soluble fraction (CTSF) of methanolic crude extract showed moderate antimicrobial activity (zone of inhibition = 8.0-15.0 mm) against the test organisms (Table 6). The carbon tetrachloride partitionate exhibited maximum antimicrobial activity against $B$. megaterium $(15.0 \mathrm{~mm})$ and $S$. Paratyphi $(13.0 \mathrm{~mm})$ while the crude methanolic extract of $S$. suaveolens and its aqueous soluble fraction showed little or no activity against the test organisms at the test dose (data not shown).

\section{REFERENCES}

1. Rashid, M.A., Haque, M.R., Sikder, M.A., Chowdhury, A.A., Rahman, M.S. and Hasan, C.M. 2014. Review on chemistry and bioactivities of secondary metabolites from some medicinal plants and microbes of Bangladesh. Bangladesh Pharm. J. 17, 63-79.

2. Agrawal, S.S. and Paridhavi, M. 2007. Herbal drug technology. University press (India) private limited. pp. 321439.

3. Ghani, A. 2003. Medicinal Plants of Bangladesh: Chemical constituents and uses. 2nd edition, Asiatic Society of Bangladesh, Dhaka.

4. Meena, A.K., Yadav, A.K., Panda, P., Preet, K. and Rao, M.M.2010. Review on Stereospermum suaveolens DC: A potential herb. Drug Invention Today 2, 238-239.

5. Srivastava, N., Khatoon, S., Rawat, A.K., Rai, V. and Mehrotra, S.2009. Chromatographic estimation of pcoumaric acid and triacontanol in an ayurvedic root drug patala (Stereospermum suaveolens Roxb.). J. Chromatogr. Sci. 47, 936-939.

6. Yoganarasimhan, S.N. Vol. 2. Tamilnadu, India: Cybermedia; 2000. Medicinal plants of India.

7. Gupta, A.K., Neeraj, T. and Madhu, S. 2008. New Delhi: medicinal plants unit Indian Council Medical Research. Quality Standards of Indian medicinal plants, pp. 290-297.

8. Subramanian, S.S., Nagarajan, S. and Sulochana, M.N. 1972. Flavonoids of the leaves of Stererospermum suaveolens. Curr. Sci. 41, 102-103.

9. Haque, M.R., Rahman, K.M., Iskander, M.N., Hasan, C.M. and Rashid, M.A. 2006. Stereochenols A and B, two quinones from Stereospermum chelonoides. Phytochemistry 67, 2663-2665.
10. Ramachandran, A.G. and Kotiyal, J.P. 1979. Stereolensin: A new flavone glucoside from Stereospermum suaveolens. Indian J. Chem. 18B, 188-189.

11. Faruq, A.A., Ibrahim, M., Chowdhury, M.M.U., Haque, M.R. and Rashid, M.A. 2017. Pharmacological and biological activities of different fractions methanol extracts of Gardenia coronaria Buch.-Ham. Leaves. Bangladesh Pharm. J. 20, 139-147.

12. Anjum, A., Sultan, Z.M., Hasan, C.M. and Rashid, M.A. 2017. Antibacterial and cytotoxic constituents from Bridelia verrucosa Haines growing in Bangladesh. Dhaka Univ. J. Pharm. Sci. 16, 61-68.

13. Dasgupta, T., Ganguly, A., Asaduzzaman, M. and Qais, M. 2016. Evaluation of anti-microbial, hypoglycemic andantidiarrheal activities of Setaria italicaseeds. Dhaka Univ. J. Pharm. Sci. 15, 31-35.

14. Shoba, F.G. and Thomas, M.2001. Study of antidiarrhoeal activity of four medicinal plants in castor oil-induced diarrhea. J. Ethnopharmacol. 76, 73-76.

15. Hussain, F., Ganguly, A., Hossain, M.S. and Rahaman, S.M.A. 2014. Analgesic and anti-diarrhoeal activity of roots in experimental animal model. Dhaka Univ. J. Pharm. Sci. 13 57-62.

16. Koster, R., Anderson, M. and De Beer, E.J. 1959.Acetic acid for analgesic screening. Proc. Soc. Exp. Biol. Med. 1, 412415.

17. Skerget, M., Kotnik, P., Hadolin, M., Hras, A., Simonic, M. and Knez, Z. 2005. Phenols, proanthocyanidins, flavones and flavonols in some plant materials and their antioxidant activities. Food Chem. 89, 191-198.

18. Brand-Williams, W., Cuvelier, M.E. and Berset, C. 1995. Use of free radical method to evaluate antioxidant activity. Lebensm Wiss. Technol. 28, 25-30.

19. Prasad, S., Kashyap, R.S., Deopujari, J.Y., Purohit, H.J., Taori, G.M. and Daginawala, H.F. 2006. Development of an in vitro model to study clot lysis activity of thrombolytic drugs. Thrombosis J. 4, 14.

20. Shinde, U.A., Phadke, A.S., Nair, A.M., Mungantiwar, A.A., Dikshit, V.J. and Saraf, M.N. 1999. Membrane stabilizing activity-a possible mechanism of action for the antiinflammatory activity of Cedrus deodara wood oil. Fitoterapia 70, 251-257.

21. Bauer, A.W., Kirby, W.M., Sherris, J.C. and Turck, M. 1966. Antibiotic susceptibility testing by a standardized single disk method. Am. J. Clin. Pathol. 45, 493-496. 